\title{
Salt Lake City, Andre Agassi and Irene Davis: BJSM's letter from the Americas...
}

\section{Karim M Khan}

February 1st already-can you believe it? Just 2-3 months until American Medical Society for Sports Medicine's (AMSSM) 20th annual meeting-Salt Lake City, 30 April-4 May, 2011. This meeting is now famous for its collegial spirit, the sense of 'community' for sports physicians. AMSSM welcomes newcomers, and the family atmosphere is wonderful for partners.

The meeting focuses squarely on primary care sports medicine-see the conference programme on the BJSM Blog (http://blogs. bmj.com/bjsm/). Slide in for the schussing (cover image), and go home with new friends, new clinical tools, and new ideas for practice management. If you are on the job market, I can assure you this is the hub of fellowship wheeling and dealing.

The programme is the best ever-really exciting. Critical themes-ACL, osteoarthritis in sport, gait analysis and retraining, sports medicine imaging and the role of neuropsych testing in concussion management-are covered by luminary speakers. Irene Davis, Elizabeth Arendt and Fran O'Connor are just the tip of an iceberg of faculty wisdom.

Innovations such as practice pearls for faculty development, extreme sports, and tips on managing the underperforming athlete run alongside debates on what is 'too thin to train' or whether Mixed Martial Arts and boxing should be left without medical coverage. Conference veterans know that 'Pardon the Interruption' is standing room only!

\section{AGASSI'S OPEN-A GREAT READ}

Just 362 miles from SLC yet a world apart is Las Vegas-the birthplace and home of Andre Agassi. Parental influence is a sports medicine topic (see January 2010 $B J S M$ theme issue and podcast-Dennis Caine http://tiny.cc/xsx0x). As a 16-yearold, Agassi was faced with deciding

Correspondence to Dr Karim M Khan, University of British Columbia, Vancouver, BC V6T 1Z4, Canada; karim.khan@ubc.ca whether to accept a runner-up cheque for $\$ 1100$. He needed the money, but taking it would mean losing his amateur status... He rang his dad for advice. 'What the hell do you mean? Take the money'. Andre countered, 'If I take the money Dad, there's no turning back. I'm pro.'... His dad acted as if there was a bad connection. 'You've dropped out of school! You have an eighth-grade education. What are your choices? What the hell else are you going to do? Be a doctor?'1

For those who haven't read the book, Agassi set up a College Preparatory Academy and educational foundation in West Las Vegas. He closes by writing that he was late in discovering the magic of books. 'Of all my many mistakes that I want my children to avoid, I put that one near the top of the list'.

\section{NSAID USE-IN MAJOR GAMES AND IN TRIATHLON}

Agassi comments on non-steroidal antiinflammatory drugs (NSAIDs) and other drugs but skip that for two new studies from Brazil where BJSM is widely read. Gorski and colleagues found that $60 \%$ of ironman triathletes used NSAIDs in the 3 months leading up to the Brazil Ironman Triathlon (see page 85). The innovation in the paper is the survey of athlete's knowledge and rationale for use. Clearly, evidence-based practice has not hit the athlete users yet! And 5 years out from the Rio Olympic Games, Da Silva and colleagues (see page 91) share the antidoping test data from the 2007 Pan American Games. As the Apollo 13 astronauts are reported as saying 'Houston, we have a problem.' (Houston=1503 miles from SLC; outer space is much further).

\section{EDUCATIONAL ISSUES IN SPORTS AND EXERCISE MEDICINE}

While conscious of our large physiotherapy relevance and readership, this issue of BJSM focuses on sports and exercise medicine leaders from the UK and Australia who editorialise highly topical issues. Mark Batt and Rod Jaques provide a perspective on the universal issue of continued education and revalidation (see page 80). This is relevant for all clinicians-not just MDs. Cathy Speed and the busy Rod Jaques put high-performance sports medicine in a historical perspective and look forward (see page 81). This also requires a team approach to clinical care-a foundation stone of our field. And Paul McCrory and Andrew Franklyn Miller took time off from promoting their lovely new book, Clinical Sports Anatomy (Franklyn-Miller, 2011), to write about the challenges of incorporating evidence into practice (see page 83). It's not easy but they argue it is essential for all clinicians if we are to differentiate ourselves from snakeoil salesmen.

\section{BMJ LEARNING AND FREE PODCASTS/BLOG}

Consider BMJ Learning's elements relating to ankle sprain management and Achilles problems (http://learning.bmj. com/learning/main.html). If you have problems accessing the site, let us know (bjsm@bmjgroup.com). In addition, there are over a dozen podcasts freely available at bjsm.bmjgroup.com-just click on the big 'podcast' panel. We aim to blog at least four times a week, and Twitter(@ BJSM_BMJ) will keep you abreast of not only our blog updates but also the best retweets from the 100 or so physiotherapy- and medicine-related sites we monitor. See you in Salt Lake City, and if you can't make that, see the BJSM Blog (bmj. $\mathrm{com} / \mathrm{bjsm} /$ category/conferences/) for other major sport and exercise medicine conferences this year-it's an exciting time in our field!

Competing interests Karim Khan is an author with McGraw-Hill who publish Franklyn-Miller's book Clinical Sports Anatomy mentioned here. Karim wrote the foreword for the book and receives no financial benefit from sales of Clinical Sports Anatomy.

Provenance and peer review Not commissioned; not externally peer reviewed.

Accepted 17 December 2010

Br J Sports Med 2011;45:79 doi:10.1136/bjsm.2010.083162

\section{REFERENCES}

. Agassi A. Open. London, UK: Harper Collins 2010.

2. Franklyn-Miller A, Falvey E, McCrory P, et al. Clinical Sports Anatomy. North Ryde, Australia: McGraw-Hill 2011. 